\title{
RANCANGAN PEMBELAJARAN JARINGAN KOMPUTER MODEL DICK DAN CAREY BERBASIS MANAJEMEN LAYANAN INFORMATION TECHNOLOGY INFRASTRUCTURE LIBRARY (ITIL)
}

\author{
Qammaddin, Sulfikar Sallu \\ Fakultas Teknologi Informasi, Universitas Sembilanbelas November, Kolaka Sulawesi \\ Tenggara \\ sulfikar.sallu@gmail.com
}

\begin{abstract}
Computer Network Learning is one of the teaching and learning processes in the compulsory Computer Networking course in a study program in the computer science family. Dick and Carey designs are the general components of a learning material from the procedures that will be used in learning to produce the desired learning outcomes. Furthermore, Information Technology Infrastructure Library (ITL) is one of the frameworks that is part of Service Management in IT governance to make it easier to evaluate IT services and to find out things that must be developed in that service. The purpose of this study was to produce a design concept in the ITL-based dick and carey model of computer network learning design. The method used is a literature review that utilizes all available reference sources. The result achieved is the ITL-based Dick and Carey model computer network course concept which will create a quality computer network learning design.
\end{abstract}

Keywords: Learning Design, Computer Networking, Dick and Carey, ITL Management

\section{$A B S T R A K$}

Pembelajaran Jaringan Komputer merupakan salah satu proses belajar mengajar dalam mata mata Kuliah Jaringan Komputer wajib pada sebuah program studi Fakultas Teknologi Informasi Universitas Sembilanbelas November (FTI USN) dalam rumpun ilmu komputer. Desain Dick and Carey adalah komponen-komponen umum dari suatu bahan pembelajaran dari prosedur-prosedur yang akan digunakan dalam pembelajaran untuk menghasilkan hasil belajar yang diinginkan. Selanjutnya Information Technology Infrastructure Library (ITL) adalah salah satu framework yang merupakan bagian dari Service Management dalam tata kelola IT untuk mempermudah dalam mengevaluasi layanan IT dan untuk mengetahui hal-hal yang harus dikembangkan dalam layanan itu. Tujuan penelitian ini adalah untuk menghasiilkan konsep rancangan dalam desain pembelajaran jaringan komputer model Dick and Carey berbasis ITL. Metode yang digunakan adalah literature review yang memanfaatkan seluruh sumber referensi yang ada. Hasil yang dicapai adalah konsep mata Kuliah Jaringan Komputer model Dick dan Carey berbasis ITL yang akan menciptakan desain pembelajaran jaringan komputer berkualitas.

Kata kunci: Desain Pembelajaran, Jaringan Komputer, Manajemen ITL

\section{PENDAHULUAN}

Mata Kuliah Jaringan Komputer merupakan salah satu mata kuliah Jaringan wajib dalam rumpun ilmu komputer. Model pembelajaran yang berlangsung pada saat ini telah mengalami perkembangan yang cukup maju seiring dengan perkembangan teknologi informasi. Pengamatan pada mahasiswa FTI USN peserta kuliah Jaringan Komputer yang sudah berjalan menunjukkan bahwa suasana pembelajaran kurang kondusif, meskipun pembelajaran mengacu pada pembelajaran yang kontekstual. Hal itu terlihat dari proses pembelajaran hanya sedikit yang mengajukan dan menjawab 
pertanyaan, masih ada mahasiswa yang menggantungkan nilai pada teman, yaitu pada saat pembuatan tugas kelompok, selama pembelajaran mahasiswa diliputi perasaan malas karena banyak sekali istilah-istilah maupun konsep dalam Jaringan Komputer yang sulit dimengerti, dan mahasiswa cenderung merasa bosan karena di samping sulitnya memahami materi, juga karena metode pembelajaran yang hampir sama dengan kuliah yang lain.

Penelitian ini dilakukan untuk meningkatkan kualitas proses pembelajaran mata Kuliah Jaringan Komputer dengan merancang pembelajaran menggunakan model Dick dan Carey dengan memanfaat-kan layanan ITL.

Masalah yang akan dipecahkan adalah mengubah pola pikir pembelajaran mahasiswa FTI USN yang mengambil mata kuliah jaringan komputer yang selama ini banyak dilakukan hanya berdasarkan teori yang tidak mengikuti perkembangan zaman.

Tujuan penelitian ini adalah untuk menemukan model pembelajaran Jaringan Komputer dengan memadukan model pembelajaran Dick dan Carey dengan jaringan komputer menggunakan layanan ITL.

Inovasi penelitian ini adalah melakukan pembelajaran model dick and carey dalam praktikum berbasis digital dengan memanfaatkan layanan ITL, sehingga proses praktek jaringan komputer dapat dilakukan dari mana saja dan kapan saja.

Layanan ITL merupakan salah satu model layanan yang dapat digunakan dalam sebuah desain pembelajaran mata kuliah Jaringan Komputer baik teori maupun praktek.

Pada dasarnya konsep dasar dari sistem jaringan komputer sebagian besar dari materi tersebut bersifat abstrak sehingga banyak mahasiswa mengalami kesulitan dalam memahaminya (Paryanta, 2016). Oleh karena itu diperlukan adanya peningkatan mutu pembelajaran, misalnya melakukan simulasi terlebih dahulu sebelum mengimplementasikannya dengan perangkat keras yang sesungguhnya. Sistem pembelajaran merupakan satu kesatuan dari beberapa komponen pembelajaran yang saling berinteraksi, interelasi dan interdependensi dalam mencapai tujuan pembelajaran yang telah ditetapkan. Komponen pembelajaran meliputi; peserta didik, pendidik, kurikulum, bahan ajar, media pembelajaran, sumber belajar, proses pembelajaran, fasilitas, lingkungan dan tujuan

\section{KAJIAN LITERATUR}

Desain pembelajaran adalah pengembangan secara sistematis dari spesifikasi pembelajaran dengan menggunakan teori belajar dan pembelajaran untuk menjamin kualitas pembelajaran. Proses perancangan dan pengembangan ini meliputi segala proses analisis kebutuhan pembelajaran, tujuan dan pengembangan sistem untuk mencapai tujuan, pengembangan bahan dan aktivitas pembelajaran, uji coba dan evaluasi dari seluruh pembelajaran dan aktivitas peserta didik. Desain pembelajaran merupakan kegiatan memaksimalkan efektifitas, efisiensi, hasil pembelajaran, dan pengalam-an pembelajaran lainnya. Kegiatan tersebut meliputi penentuan keadaan awal, kebutuhan peserta didik, menentukan tujuan akhir dan menciptakan beberapa perlakuan untuk membantu dalam masa transisi tersebut (Degeng, 2013). Di samping itu perlu pula dikemukakan bahwa desain pembelajaran berkenaan dengan proses menentukan tujuan pembelajaran, strategi dan teknik untuk mencapai tujuan serta merancang media yang dapat digunakan untuk keefektifan pencapaian tujuan.

Desain pembelajaran adalah
pengembangan dilakukan secara sistematis untuk memaksimalkan efektifitas dan efisiensi pembelajaran. Kegiatan mendesain pembelajaran diawali dengan menganalisis kebutuhan peserta didik, menentukan tujuan pembelajaran, mengembangkan bahan dan aktivitas 
pembelajaran, yang di dalamnya mencakup penentuan sumber belajar, strategi pembelajaran, langkah-langkah pembelajar-an, media pembelajaran dan penilaian (evaluasi) untuk mengukur tingkat keberhasilan pembelajaran. Hasil evaluasi tersebut digunakan sebagai acuan untuk mengetahui tingkat efektivitas, efisiensi dan produktivitas proses pembelajaran.

Revolusi teknologi informasi (TI) terjadi semakin pesat, di mana manusia telah memanfaatkan TI dalam segala aktivitas. Seiring dengan perkembangan dan kemanfaatan teknologi informasi tersebut timbul beberapa tuntutan implementasi pada tingkatan yang mengharuskan pengguna mampu memanfaatkannya sebagai ladang pengelola dan penghasil informasi yang dibutuhkan. Salah satunya adalah penggunaan berbagai media dan sarana dalam dunia pendidikan. Pemanfaatan teknologi informasi dalam menunjang administrasi akademik dan manajemen pendidikan telah membawa dunia pendidikan pada tahap yang lebih maju dan gobal. Kebutuhan untuk mendapatkan informasi dan akses secara cepat, tepat, mudah, dan tanpa batas, merupakan alasan penting peran teknologi informasi dalam dunia pendidikan (Manuputty, 2017). Kualitas rancangan dan pengembangan sistem pembelajaran dipengaruhi oleh beberapa komponen. yaitu: kemampuan awal peserta didik dan potensi yang dimiliki, tujuan pembelajaran (umum dan khusus) yang tidak lain adalah penjabaran kompetensi yang akan dikuasai oleh peserta didik, analisis materi pembelajaran yang digunakan untuk mencapai tujuan pembelajaran, analisis aktivitas pembelajaran yang merupakan proses menganalisis topik atau materi yang akan dipelajari, pengembangan media pembelajaran yang sesuai dengan tujuan, materi pembelajaran dan kemampuan peserta didik, strategi pembelajaran yang dapat dilakukan secara makro dalam kurun satu tahun atau mikro dalam kurun satu kegiatan belajar mengajar, sumber belajar yaitu sumber-sumber yang dapat diakses untuk memperoleh materi yang akan dipelajari, penilaian belajar yaitu pengukuran kemampuan atau kompetensi yang dikuasai oleh peserta didik.

Dalam merancang mata kuliah Jaringan Komputer terdapat beberapa indikator yang menjadi dasar untuk mencapai hasil yang maksimal, yaitu antara lain: kerjasama, partisipasi, keaktifan, ketepatan pemilihan metode, kebenaran menjawab, dan kemampuan menyampaikan pendapat berdasarkan pengalaman.

Implementasi TI pada sebuah perguruan tinggi telah berkembang dan mengalami pergeseran fungsi. TI tidak hanya ditempatkan pada proses pendukung seperti komputasi dan otomatisasi proses namun juga di posisikan sebagai aset strategis yang turut menentukan strategi program tinggi untuk maju. ITL sebagai salah satu layanan framework yang menyediakan serangkaian proses dan fungsi best practice dalam memberikan layanan TI khususnya dalam desain pembelajaran (Budiyono Eko Nugroho, 2012).

Sistem pendidikan tinggi yang sehat ditandai dengan kualitas perguruan tinggi yang semakin bermutu dan relevan. Selain itu, diperlukan pemerataan akses ke pendidikan tinggi yang berkualitas dan relevan dengan kebutuhan masyarakat. (Indonesia, 2021) dan ciri mata Kuliah Jaringan Komputer yang berkualitas adalah tersedianya materi pembelajaran yang dapat diakses kapan dan dari mana saja serta mengandung content kebutuhan dunia kerja, hal ini dapat dibuktikan dengan banyaknua permintaan tenaga kerja sesuai dengan kompetensi yang dihasilkan.

Layanan ITL dalam mata pelajaraan teori dalam mengekstrak aspek konten tugas yang relevan dari deskripsi tugas tekstual dan membangun model konten tugas sebagai dasar untuk pengembangan berbagai solusi pendukung keputusan untuk mahasiswa proses dan dosen (Rizun, Revina, \& Meister, 2021). Dalam penerapan manajemen layanan ITL terdapat sebuah proses. Proses yang dimaksud adalah kegiatan yang 
dirancang untuk mencapai suatu hasil yang spesifik. Di dalam sebuah proses akan dibutuhkan sebuah peran, tanggung jawab, tools dan kontrol yang baik agar memberikan sebuah hasil. Karakteristik dari sebuah proses yang baik pun mempunyai standard seperti proses tersebut harus dapat diukur dan bisa memberikan sebuah hasil yang spesifik. Di dalam proses ITL Service Management terdapat beberapa peran dengan tanggung jawab yang berbedabeda, seperti Service Owner dan Process Owner. (Us, Member, \& Portofolio, 2021). Dengan demikian layanan mata kuliah Jaringan Komputer akan semakin berkualitas.

Layanan ITL dalam mata kuliah dan permasalahan dalam penerapan suatu layanan berbasis teknologi informasi yang terintegrasi memerlukan standar data, kesiapan sistem dalam men-sharing data, ketersediaan sistem, beban penggunaan yang besar, serta keinginan pengguna untuk memanfaatkan sistem baru yang terintegrasi. Kerangka kerja ITL (Information Technology Infrastructure Libary) diperlukan untuk meninjau kembali praktek layananan pada IT Service Management dari suatu sistem layananan terintegrasi yang digunakan di perguruan tinggi.

\section{METODE PENELITIAN}

Berbagai model dapat dikembangkan dalam mengorganisasi pengajaran, satu di antaranya adalah model pengembangan pembelajaran Dick and Carrey yang digunakan dalam penelitian ini. Adapun langkah-langkah model pengembangan pembelajaran Dick dan Carey mencakup (1) mengidentifikasi tujuan instruksional umum, (2) melaksanakan analisis pembelajaran, (3) mengidentifikasi tingkah laku masukan dan karakteristik siswa, (4) merumuskan tujuan instruksional khusus, (5) mengembangkan butir butir tes acuan patokan, (6) mengembangkan strategi pengajaran, (7) mengembangkan dan memilih materi pembelajaran, (8) mendesain dan melaksanakan evaluasi formatif, (9) merevisi bahan pembelajaran, dan (10) mendesain dan melakukan evaluasi sumatif. (Aji, 2016). Langkah-langkah tersebut tampak sebagaimana gambar di bawah ini.

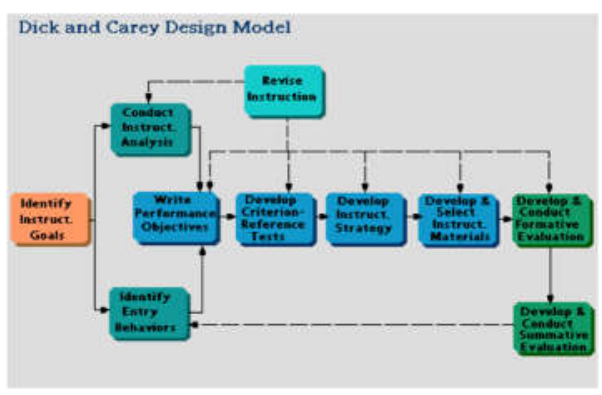

Gambar 1 Model Pembelajaran Dick and Carey (Fitria, 2013)

\section{HASIL DAN PEMBAHASAN}

Kualitas dari proses dan luaran pembelajaran selalu berhubungan satu sama lain. Proses pembelajaran yang berkualitas akan menghasilkan luaran pembelajaran yang berkualitas pula. Indikator dari proses pembelajaran yang baik diperoleh dari pemanfaatan model pembelajaran yang tepat guna mendukung dihasilkannya luaran pembelajaran yang berkualitas. Model pembelajaran Dick dan Carrey adalah salah satu model pembelajaran yang dapat digunakan dalam pembelajaran mata kuliah Jaringan Komputer di perguruan tinggi.

ITL memiliki tujuan layanan service management antara lain: untuk memastikan bahwa layanan TI dalam proses pembelajaran sejalan dengan kebutuhan perkuliahan dan secara aktif mendukung proses perkuliahan. Layanan TI yang mendukung proses perkuliahan sangatlah penting, tetapi semakin penting juga bahwa TI bertindak sebagai agen perubahan untuk memfasilitasi transformasi perkuliahan. Selanjutnya service management adalah seperangkat kemampuan khusus organisasi untuk memberikan nilai kepada pelanggan dalam bentuk layanan. Kapabilitas ini mencakup proses, cara/metode, fungsi, peran dan aktifitas dari Service Provider (penyedia jasa). 


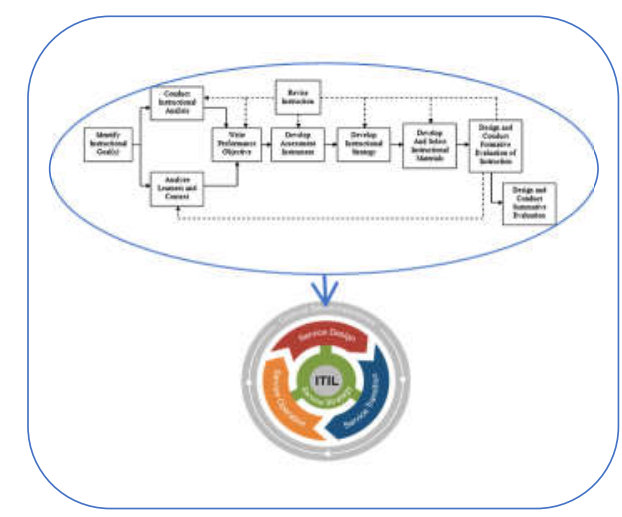

Gambar 2 Rancangan Dick dan Carey berbasis ITL

Dalam penggunaan model pembelajaran mata kuliah Jaringan Komputer Dick and Carrey adalah sebagai berikut. 1. Model Dick and Carrey terdiri atas 10 langkah yang akan disesuaikan dengan kebutuhan mata kuliah Jaringan Komputer. Setiap langkah sangat jelas maksud dan tujuannya sehingga bagi perancang sangat cocok sebagai dasar untuk mempelajari model desain yang lain dan akan di intergasikan dengan berbagai perangkat. 2. Kesepuluh langkah pada model Dick and Carrey menunjukkan hubungan yang sangat jelas dan tidak terputus antara langkah yang satu dengan langkah yang lainnya. Sistem yang terdapat dalam Dick and Carrey sangat ringkas, tetapi isinya padat dan jelas dari suatu urutan ke urutan berikutnya. 3 . Langkah awal pada model Dick dan Carrey adalah mengidentifikasi tujuan pengajaran mata kuliah Jaringan Komputer. Langkah ini sangat sesuai dengan kurikulum, baik di perguruan tinggi maupun sekolah menengah dan sekolah dasar, khususnya dalam mata kuliah Jaringan Komputer yang memiliki tujuan pembelajaran dalam kurikulumnya untuk dapat melahirkan suatu rancangan pembelajaran yang berkualitas. Penggunaan model Dick dan Carrey dalam pengembangan suatu mata pelajaran dimaksudkan agar: (a) pada awal proses pembelajaran, anak didik atau siswa dapat mengetahui dan mampu melakukan berbagai hal yang berkaitan dengan materi pada akhir pembelajaran, (b) adanya pertautan antara tiap komponen, khususnya strategi pembelajaran dan hasil pembelajaran yang dikehendaki, (c) menerapkan langkah-langah yang perlu dilakukan dalam melakukan perencanaan desain pembelajaran.

Komponen model Dick dan Carey meliputi pembelajar, pengajar, materi, dan lingkungan. $\mathrm{Di}$ lingkungan pendidikan non formal model ini meliputi warga belajar (pembelajar), tutor (pengajar), materi, dan lingkungan pembelajaran. Semua komponen berinteraksi dalam proses pembelajaran untuk mencapai tujuan yang telah ditetapkan.

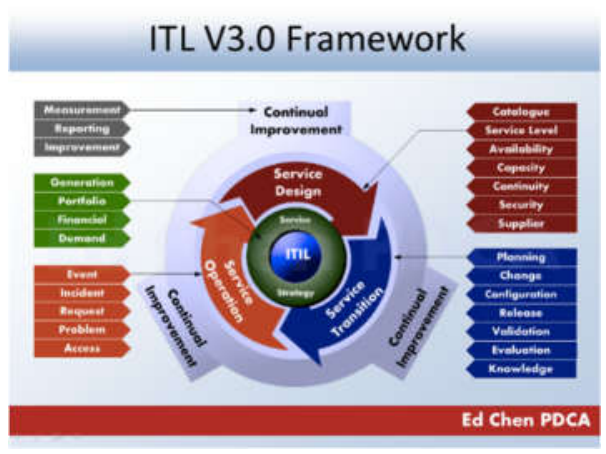

Gambar 3 ITL Framework (Pdca, 2021)

Layanan ITL adalah cara memberikan manfaat (nilai) bagi akademisi dengan usaha untuk menyediakan (memfasilitasi) hasil yang diinginkan tanpa harus mengemban biaya dan risiko tertentu.

ITL merupakan suatu kerangka kerja umum yang menggambarkan Best Practice layanan manajemen TI dalam perguruan tinggi, menyediakan kerangka kerja bagi tatakelola TI, serta wrapping layanan akademik. Layanan ini juga memfokuskan diri pada pengukuran terus menerus dan perbaikan kualitas layanan baik dari perspektif akademik maupun masyarakat luas. Di samping itu layanan ini juga fokus sebagai faktor utama dalam integrasi di seluruh dunia.

Layanan ITL sebagai layanan yang mengadopsi good practice dimaksudkan agar dapat membantu penyedia layanan akademik untuk menciptakan sistem manajemen pelayanan akademik yang efektif. Good practice pada dasarnya hanya melakukan hal-hal yang telah terbukti bekerja dan terbukti efektif yang dapat diimplementasikan dalam dunia 
pendidikan terutama perguruan tinggi. Good practice bisa berasal dari berbagai sumber, termasuk kerangka umum serta pengetahuan organisasi itu sendiri.

\section{KESIMPULAN}

Rancangan pembelajaran Dick dan Carey yang dikombinasikan dengan layanan ITL dapat meningkatkan kualitas pembelajaran dan layanan dalam sebuah perguruan tinggi.

\section{REFERENSI}

Aji, W. N. 2016. Model Pembelajaran Dick and Carrey Dalam Pembelajaran Bahasa Dan Sastra Indonesia. Kajian Linguistik Dan Sastra, $\quad 1(2), \quad 119$ https://doi.org/10.23917/kls.v1i2. 3631

Budiyono Eko Nugroho, W. W. W. 2012. Implementasi ITIL V3 Framework pada Perancangan Aplikasi Service Desk Management BerOrientasi USER. JNTETI, 1(2), 11-20. Retrieved from https://docplayer.info/46445335Implementasi-itil-v3-frameworkpada-perancangan-aplikasiservice-desk-managementberorientasi-user.html

Degeng, I. N. S. 2013. ... Mata Kuliah Administrasi Jaringan Program Studi S1 Teknik Informatika Joint Program Vedc Malang Model Dick and Carey. Retrieved from https://www.academia.edu/downl oad/33011845/01_yamta_desain_ pembelajaran_admin_server_men urut_model_dick_and_carey_ok.p df

Dosen (DM032), M. P. J. K. 2016. Rencana Pembelajaran Semester ( Rps ) Mata Kuliah: Rencana Pembelajaran Semester ( Rps ), 5(024), 1-11. Retrieved from http://d3mi.amikom.ac.id/media/0 2/02._RPS_Jarkom_MI_.pdf

Fitria. 2013. Dick dan Carey Model Dick. Retrieved from https://fdokumen.com/download/? url $=$ b70feb3e27a5baf0646d5205c 5e404d242519c6d4eaae091be928 536164b60bcd11352dfc531 eaa8a 454967c7a6f18ce95d78328ce7d1 050689cb42794a97827grrcHxtwa bqMP7yUJ4g+caguZFip3kc0kE0 vSNXmYKMlwAB7UxJEISeR9 DFsPTYgngzS8pozTHnkzqv5snu $\mathrm{cGw}==$

Handoko, Y. (n.d.). Pemanfaatan ITIL v3 untuk Mengatasi Masalah Layanan TI pada Sistem Terintegrasi di Perguruan Tinggi Using ITIL v3 to Solve IT Service Problem in Integration System at Universities.

Indonesia, M. 2021. Kampus Merdeka Menuju Pendidikan Tinggi Berkualitas. Retrieved from https://mediaindonesia.com/hutri/336536/kampus-merdekamenuju-pendidikan-tinggiberkualitas

Manuputty, A. D. 2017. Analisis Layanan Manajemen Teknologi Informasi dengan Service Strategy ITL V.3 (Studi Kasus: Fakultas Ilmu Kesehatan UKSW) Artikel Ilmiah, 3(682009078).

Paryanta. 2016. Media Pembelajaran Sistem Jaringan Komputer Dan Internet Berbantuan Komputer Dengan Model Tutorial. IJNSIndonesian Journal on Networking and Security, 5(2), 1.

Pdca, E. C. 2021. ITIL V3.0 Framework Illustrated POSTED. Retrieved June $7, \quad 2021$, from https://pdca.edchen.org/itil-v3-0framework-illustrated/

Rizun, N., Revina, A., \& Meister, V. G. 2021. Analyzing content of tasks in Business Process Management. Blending task execution and organization perspectives. Computers in Industry, 130, 103463.

https://doi.org/https://doi.org/10.1 016/j.compind.2021.103463

Us, A., Member, F., \& Portofolio, S. (2021). Siklus manajemen layanan itl 23. 